\title{
Impact of asymmetrical phenomena on asynchronous three-phase motors in operation mode
}

\author{
Y Nhu Do ${ }^{1}$, Thanh Xuan Le ${ }^{1}$, Ninh Bao Nguyen Tran ${ }^{2}$, Tuan Thanh Ngo ${ }^{1}$, \\ ${ }^{1}$ Faculty of Electro-Mechanics Hanoi University of Mining and Geology \\ ${ }^{2}$ Faculty of electrical engineering, Vinh University of Technology Education
}

\section{ARTICLE INFO}

Article history:

Received 17th Mar. 2020

Revised $13^{\text {rd }}$ June 2020

Accepted 30th June 2020

Keywords:

Asymmetry voltage,

Motor performance,

Three-phase asynchronous

motor.

\section{ABSTRACT}

The general theory of three-phase motors is often built based on the assumption that the three phases voltage is symmetrical. However, in practice, this operation mode of the motor cannot be achieved due to a number of reasons such as the structure of the motor is not symmetrical, the load in the electrical system is not balanced. The asymmetry of threephase voltage greatly affects the operation mode of a three-phase asynchronous motor. The most serious affections are: decrease the starting torque, increase stator current and rotor current, vibration inside the motor. This affection will reduce the effective operation of the motor. The paper investigates the effect of asymmetry voltage on the normal operation mode of a three-phase asynchronous motor based on the electromagnetic transforming method of electric machines and simulating on Matlab-Simulink.

Copyright (c 2020 Hanoi University of Mining and Geology. All rights reserved.

\section{Introduction}

The general theory of three-phase asynchronous electric motors is based on the assumption that the standard voltage is sinusoidal and symmetrical. However, in practice this cannot be achieved due to the basic causes: the structure of motors is asymmetric; the three-phase load is unbalanced, making the supply voltage asymmetric. This causes an asymmetric voltage on the three phases of the motor. This unbalancing makes the parameters of the motor

${ }^{*}$ Corresponding author

E-mail: donhuy@humg.edu.vn

DOI: 10.46326/JMES.2020.61(3).08 biased from the theory and leads to ineffective operation of three-phase asynchronous motors (DavarMirabbasi, GhodratollahSeifossadat, Mehrdad Heidari,2009; Victoria Romanova \& Sergey Khromov, 2018; Prashanna Dev Bhatarai Louisiana, 2013).

When the three-phase voltage in the motor winding is asymmetric, electromagnetic in the winding of the motor can be converted into positive-sequence components $F_{1}$, negativesequence component $\mathrm{F}_{2}$ and zero-sequence component $F_{0}$. Those components are determined by the formula (Do Nhu Y, 2018; V.Gia Hanh et al., 2001):

- The positive sequence component of the three-phase winding: 


$$
\mathrm{F}_{1(3)}=\sum_{v=6 \mathrm{k} \pm 1}\left(\frac{3}{2} \mathrm{~F}_{1 \mathrm{fv}} \sin (\omega \mathrm{t} \pm v \alpha)\right)
$$

Where: $\alpha$ - is the space angle, $v$ - order of the wave, $F_{f v}$ - is the magnitude of wave ordered $v$.

- Negative-sequence component of threephase windings:

$$
\mathrm{F}_{2(3)}=\sum_{v=6 \mathrm{k} \pm 1}\left(\frac{3}{2} \mathrm{~F}_{2 \mathrm{fv}} \sin (\omega \mathrm{t} \pm v \alpha)\right)
$$

- The zero-sequence component in the 3phase winding creates the electromagnetic fields which have the same phase-time and have symmetric phase angle. This quantity is expressed by:

$$
\begin{aligned}
& F_{01}=F_{0 f v} \sin \omega t \cos v \alpha \\
& \mathrm{F}_{02}=\mathrm{F}_{0 f v} \sin \omega \mathrm{t} \cos \left(v \alpha-\frac{2 \pi}{3}\right) \\
& \mathrm{F}_{03}=\mathrm{F}_{0 \mathrm{fv}} \sin \omega \mathrm{t} \cos \left(v \alpha-\frac{4 \pi}{3}\right)
\end{aligned}
$$

Dividing the zero-sequence waves into wave groups: $v=3 \mathrm{k}, v=6 \mathrm{k} \pm 1$. The waves ordered $v=$ $6 \mathrm{k} \pm 1$, generates electromagnetic in the form of space vectors spaced-symmetric. The vectors have a sum of total of zero. The waves ordered $v=$ 3k generates 3 phase-electromagnetic which are space-lagged $2 \mathrm{k} \pi$ in angle, and have the total:

$$
\mathrm{F}_{0(3)}=\sum_{v=3 \mathrm{k}}\left(\frac{3}{2} \mathrm{~F}_{0 \mathrm{fv}} \sin \omega \mathrm{t} \cos v \alpha\right)
$$

Thus, through the above analysis, it can be seen that: zero sequence components (3) mainly generates a dispatching magnetic field, causing an increase of heat transfer in electric motors. The positive sequence components (1) generate the magnetic field and the electromagnetic torque revolving forward in the same direction with the voltage source corresponding to the wavelength $v=1,7,13,19, \ldots$ Negative-sequence components (2) with wavelength $v=5,11,17, \ldots$ creates a magnetic field and electromagnetic torque in the opposite direction. The appearance of the positive sequence components, the negative-sequence components, and the higher-order waves in these components lead to the changing speed of the electric motor. Because of having higher-order wave components, the torque of a motor fluctuates, the motor is vibrated, as shown in Figure 1.

\section{Effect of asymmetric phenomena on three- phase asynchronous motor's operation}

\subsection{Building a model of motor-operated under asymmetric voltage}

In order to analyze the effect of asymmetry phenomenon on the operation of three-phase asynchronous motors, it is necessary to formulate a model to replace the positive and negativesequence components on a phase as shown in Figure 2 and Figure 3 (Davar Mirabbasi, et al., 2009; Prashanna Dev Bhatarai Louisiana, 2013).

When the three-phase voltage is asymmetrical, the slip coefficient is determined by the formula (Prashanna Dev Bhatarai Louisiana, 2013):

$$
s=\frac{\omega_{\mathrm{s}}-\omega_{\mathrm{r}}}{\omega_{\mathrm{s}}}
$$

Where: $\omega_{\mathrm{s}}$ - the angular speed of the stator magnetic field, $\omega_{\mathrm{r}}$ - the rotating speed of the rotor.

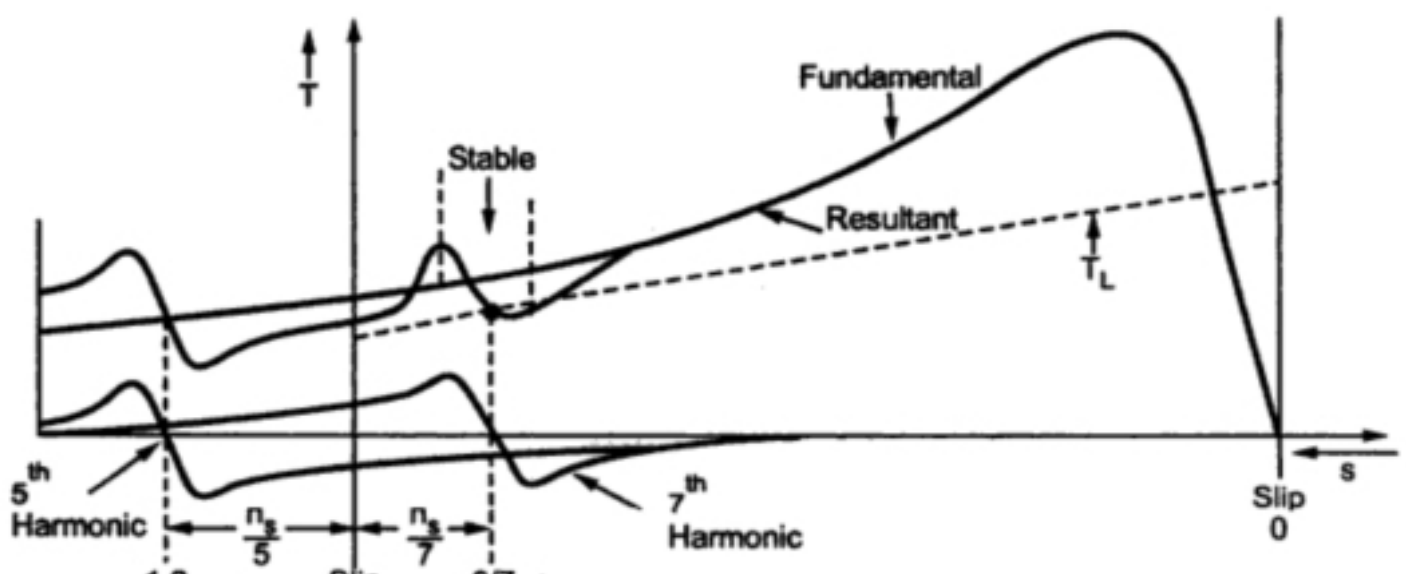

Figure 1. Characteristics of a three-phase asynchronous motor. 


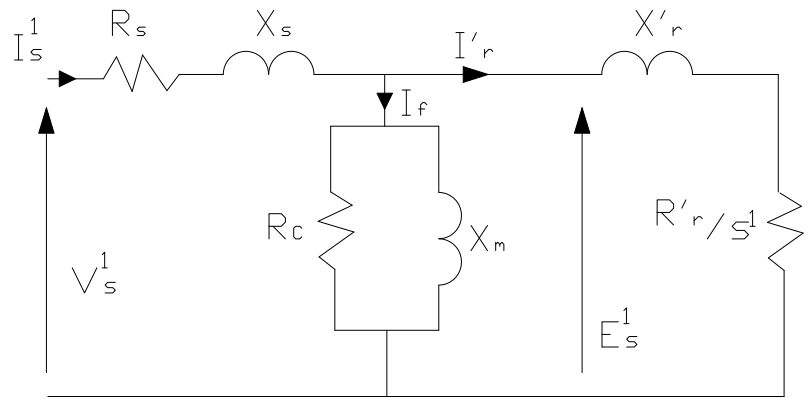

Figure. 2. Substitution diagram of the positivesequence component.

When the three-phase voltage is asymmetrical, the slip coefficient consisting of 2 mentioned components is defined by:

$$
\mathrm{s}^{1}=\frac{\omega_{\mathrm{s}}-\omega_{\mathrm{r}}}{\omega_{\mathrm{s}}}=1-\frac{\omega_{\mathrm{r}}}{\omega_{\mathrm{s}}} ; \mathrm{s}^{2}=\frac{-\omega_{\mathrm{s}}-\omega_{\mathrm{r}}}{-\omega_{\mathrm{s}}}=1+\frac{\omega_{\mathrm{r}}}{\omega_{\mathrm{s}}}(8)
$$

Where: $s^{1}$ - positive-sequence slip coefficient; $\mathrm{s}^{2-}$ Negative-sequence sliding coefficient (the default index " 1 " corresponds to positivesequence, index "2" corresponds to negativesequence).

Let:

$$
\mathrm{K}_{\mathrm{u}}=\frac{\omega_{\mathrm{r}}}{\omega_{\mathrm{s}}}
$$

Consequently:

$$
s^{1}=1-K_{u} ; \quad s^{2}=1+K_{u}
$$

\subsection{Influence on the electromagnetic torque of the three-phase asynchronous motor}

When the three-phase voltage is symmetrical, the electromagnetic power of the motor is determined by the formula (Prashanna Dev Bhatarai Louisiana, 2013):

$$
\mathrm{P}_{\mathrm{dt}}=3 \frac{\mathrm{R}_{\mathrm{r}}^{\prime} \mathrm{V}_{\mathrm{s}}^{2}}{\mathrm{~s}}\left(\mathrm{I}_{\mathrm{r}}^{\prime}\right)^{2}=\frac{3 \mathrm{R}_{\mathrm{r}}^{\prime} \mathrm{V}_{\mathrm{s}}^{2}}{s\left[\left(\frac{\mathrm{R}_{\mathrm{r}}}{\mathrm{s}}\right)^{2}+\left(\mathrm{x}_{\mathrm{r}}^{\prime}\right)^{2}\right]}
$$

Where: $R_{r}^{\prime}$ - rotor resistance refers to the stator, $\mathrm{V}_{\mathrm{s}}$ - voltage of stator, $I_{r}^{\prime}$ - rotor current converted to the stator; $X_{r}^{\prime}$ - rotor reactance converted to the stator.

Since the values of rotor resistance and rotor reactance converted to the stator side are proportional to the values of rotor resistance and rotor reactance, the above expression can be rewritten as:

$$
P_{d t}=\frac{3 R_{r} V_{s}^{2}}{s\left[\left(\frac{R_{r}}{s}\right)^{2}+\left(X_{r}\right)^{2}\right]}
$$

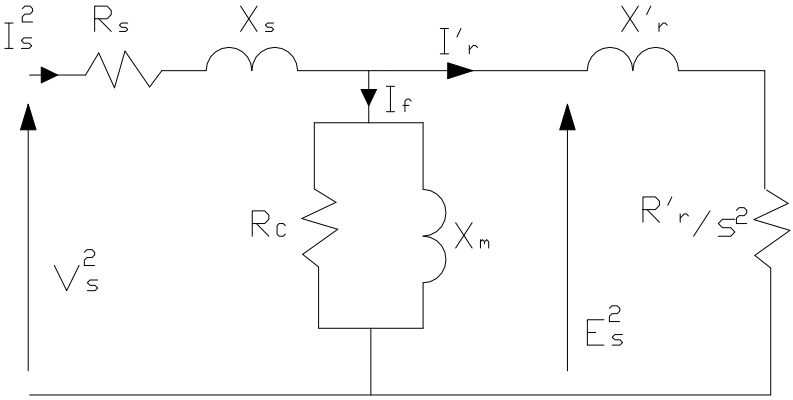

Figure 3. Substitution diagram of the negative-sequence component.

Where: $R_{r}, X_{r}$ - resistor and reactance of rotor circuit.

When the three-phase voltages are asymmetry, the total electromagnetic power of the motor is determined:

$$
\begin{gathered}
P_{d t}=P_{d t}^{1}+P_{d t}^{2} \\
P_{d t}^{1}=\frac{3 R_{r}\left(V_{s}^{1}\right)^{2}}{s^{1}\left[\left(\frac{R_{r}}{s^{1}}\right)^{2}+\left(X_{r}\right)^{2}\right]} ; P_{d t}^{2}=\frac{3 R_{r}\left(V_{s}^{2}\right)^{2}}{s^{2}\left[\left(\frac{R_{r}}{s^{2}}\right)^{2}+\left(X_{r}\right)^{2}\right]}
\end{gathered}
$$

Where: $V_{s}^{1}$ and $V_{s}^{2}$ - positive-sequence voltage and negative-sequence on the stator side.

The electromagnetic torque of the motor is determined by the formula:

$$
T=\frac{P_{d t}}{\omega_{s}}
$$

When the three-phase voltage is not symmetrical, the electromagnetic torque consists of two above components and is determined by the formula (Davar Mirabbasi et al., 2009; Victoria Romanova \& Sergey Khromov, 2018; Prashanna Dev Bhatarai Louisiana, 2013):

$$
\begin{aligned}
T^{1} & =\frac{P_{d t}^{1}}{\omega_{s}}=\frac{3 R_{r}\left(V_{s}^{1}\right)^{2}}{s^{1}\left[\left(\frac{R r}{s^{2}}\right)^{2}+\left(X_{r}\right)^{2}\right] \cdot \omega_{s}} \\
T^{2} & =\frac{P_{d t}^{2}}{-\omega_{s}}=\frac{-3 R_{r}\left(V_{s}^{2}\right)^{2}}{s^{2}\left[\left(\frac{R r}{s^{2}}\right)^{2}+\left(X_{r}\right)^{2}\right] \cdot \omega_{s}}
\end{aligned}
$$

Resulted in electromagnetic torque:

$$
\begin{gathered}
T=T^{1}+T^{2} \\
=\frac{3 R_{r}\left(V_{s}^{1}\right)^{2}}{s^{1}\left[\left(\frac{R_{r}}{s^{1}}\right)^{2}+\left(X_{r}\right)^{2}\right] \cdot \omega_{s}}-\frac{3 R_{r}\left(V_{S}^{2}\right)^{2}}{s^{2}\left[\left(\frac{R}{s^{2}}\right)^{2}+\left(X_{r}\right)^{2}\right] \cdot \omega_{s}}
\end{gathered}
$$

Making the transformation, the torque could be calculated as:

$$
\begin{aligned}
T= & \frac{3 R_{r}}{\omega_{s}}\left\{\frac{\left(V_{s}^{1}\right)^{2}}{\left(1-K_{u}\right)\left[\left(\frac{R r}{1-K_{u}}\right)^{2}+\left(X_{r}\right)^{2}\right]}-\right. \\
& \left.\frac{\left(V_{s}^{2}\right)^{2}}{1+K_{u}\left[\left(\frac{R_{r}}{1+K_{u}}\right)^{2}+\left(X_{r}\right)^{2}\right]}\right\}
\end{aligned}
$$




$$
\begin{gathered}
T=\frac{3 R_{r}\left(V_{s}^{1}\right)^{2}\left(1-K_{U}\right)}{s^{1}\left[\left(\frac{R_{r}}{s^{1}}\right)^{2}+\left(1-K_{U}\right)^{2}\left(X_{r}\right)^{2}\right] \cdot \omega_{s}}- \\
\frac{3 R_{r}^{2}\left(V_{s}^{2}\right)^{2}\left(1-K_{U}\right)}{s^{2}\left[R_{r}^{2}+\left(1-K_{U}\right)^{2}\left(X_{r}\right)^{2}\right] \cdot \omega_{s}} \\
\Rightarrow T=\frac{3 R_{r}\left(V_{S}^{1}\right)^{2}\left(1-K_{u}\right)}{\left[\left(R_{r}\right)^{2}+\left(1-K_{u}\right)^{2}\left(X_{r}\right)^{2}\right] \cdot \omega_{s}} \\
\quad-\frac{3 R_{r}\left(V_{s}^{1}\right)^{2}\left(1-K_{u}\right)}{\left[\left(R_{r}\right)^{2}+\left(1-K_{u}\right)^{2}\left(X_{r}\right)^{2}\right] \cdot \omega_{s}}
\end{gathered}
$$

When the three-phase voltage is asymmetrical, the starting torque of the motor determined by the equation:

$$
T_{K D}=\frac{3 R_{r}\left(V_{S}^{1}\right)^{2}}{\left[\left(R_{r}\right)^{2}+\left(X_{r}\right)^{2}\right] \cdot \omega_{s}}-\frac{3 R_{r}\left(V_{S}^{1}\right)^{2}}{\left[\left(R_{r}\right)^{2}+\left(X_{r}\right)^{2}\right] \cdot \omega_{s}}
$$

Comparing with the starting torque when the three-phase voltage is symmetrical, which is determined by the expression:

$$
T_{M M}=\frac{3 R V^{2}}{\left[R^{2}+X^{2}\right] \cdot \omega}
$$

From the above two equations, it can be seen that, when the three-phase voltage is asymmetric, the torque of the motor is reduced by an amount equal to the negative-sequence torque. When the asymmetry of the three-phase voltage is bigger, the reduction of torque is bigger.

\subsection{Effect on current anpd loss in motor}

When three-phase voltage is symmetrical, the rotor current is calculated approximately by the formula:

$$
I_{r}^{2}=\frac{V_{s}^{2}}{\left(\frac{R_{r}}{s}\right)^{2}+\left(X_{r}\right)^{2}}
$$

When the three-phase voltage is not symmetrical, the current on the rotor consists of two positive and negative components and is determined by the formula:

$$
\left(I_{r}^{1}\right)^{2}=\frac{\left(V_{2}^{1}\right)^{2}}{\left(\frac{R_{r}}{s^{1}}\right)^{2}+\left(X_{r}\right)^{2}} ;\left(I_{r}^{2}\right)^{2}=\frac{\left(V_{2}^{2}\right)^{2}}{\left(\frac{R_{r}}{s^{2}}\right)^{2}+\left(X_{r}\right)^{2}}
$$

From the above analysis, it's found that the rotor's current on the rotor would also increase to a quantity by the negative-component current. The rotor current is also increased to increase the negative-sequence torque in order to compensate for the negative-sequence torque for maintaining the load torque. Increased current on the rotor means that the current on the stator increases, and the loss on the motor will also increase.

Losses of the motor mainly occur in the rotor and stator circuits; however, the losses in the stator circuit are much smaller than the losses in the rotor circuit. Therefore, they eliminate the loss on the stator circuit and consider other types of losses to be unchanged. The losses on the rotor are determined by the formula (Prashanna Dev Bhatarai Louisiana, 2013; P Giridhar Kini, R C Bansal, R SAithal., 2006; Donald W. Novotny, Syed A. Nasar., 1991):

$$
\Delta P_{\text {Cu2 }}=3 R_{r} I_{r}^{2}=s P_{d t}=\frac{3 R_{r} V_{s}^{2}}{\left[\left(\frac{R_{r}}{s}\right)^{2}+\left(X_{r}\right)^{2}\right]}
$$

When the three-phase voltage is not symmetrical, the loss consists of two components: $\Delta P_{C u 2}^{1}=\frac{3 R_{r}\left(V_{s}^{1}\right)^{2}}{\left[\left(\frac{R_{r}}{s^{1}}\right)^{2}+\left(X_{r}\right)^{2}\right]} ; \Delta P_{C u 2}^{2}=\frac{3 R_{r}\left(V_{s}^{2}\right)^{2}}{\left[\left(\frac{R_{r}}{s^{2}}\right)^{2}+\left(X_{r}\right)^{2}\right]}$ (27)

The total load-loss on the rotor is determined

$$
\begin{gathered}
\Delta P=\Delta P_{C u 2}^{1}+\Delta P_{C u 2}^{2} \\
=\frac{3 R_{r}\left(V_{S}^{1}\right)^{2}}{\left[\left(\frac{R_{r}}{s^{1}}\right)^{2}+\left(X_{r}\right)^{2}\right]}+\frac{3 R_{r}\left(V_{S}^{2}\right)^{2}}{\left[\left(\frac{R_{r}}{s^{2}}\right)^{2}+\left(X_{r}\right)^{2}\right]}
\end{gathered}
$$

Compared to the expression on the motor loss when the three-phase voltage is symmetrical, the loss on the motor also increases by an amount equal to the negative sequence component.

\section{Research and evaluate the simulation model}

In order to evaluate the above analysis results, build up a simulating model to assess the effect of voltage asymmetry phenomenon on the operation of three-phase asynchronous motors on Matlab-Simulink. The simulation is implemented with two three-phase asynchronous motors D1 and D2, which are supplied by asymmetric three-phase sources (1) and symmetrical three-phase sources (2). The simulation diagram is shown in Figure 4.

The simulation results of motor parameters during the motor's operation are obtained and shown in Figure 5, Figure 6, and Figure 7.

The simulation on Fig. 5 shows that: (1) When the applied current is asymmetric (red curve-line number 2), the starting process of the motor is longer, the time for achieving the rated speed is $1 \mathrm{~s}$. This duration is longer than 0,8 s-the starting time of the symmetry state. (2) the rotating speed is lower in starting duration (red line 2 is under blue line 1); moreover, this speed is unstable (there is a fluctuation in line 2).

In Figures 6 and 7, when the voltage and current are asymmetric, the rotor current and stator current (line 2) is much fluctuated 

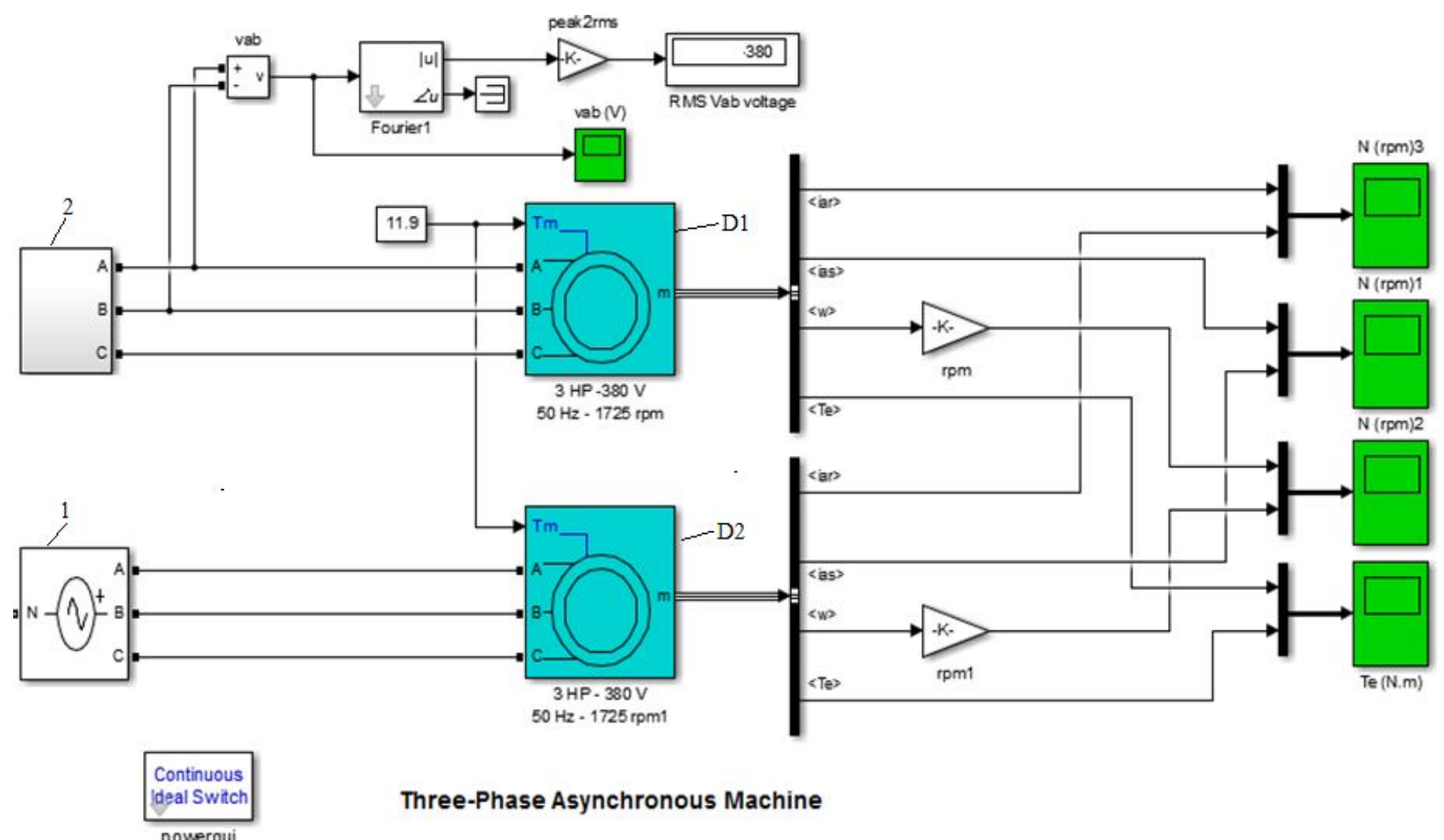

Figure 4. Matlab simulation diagram.

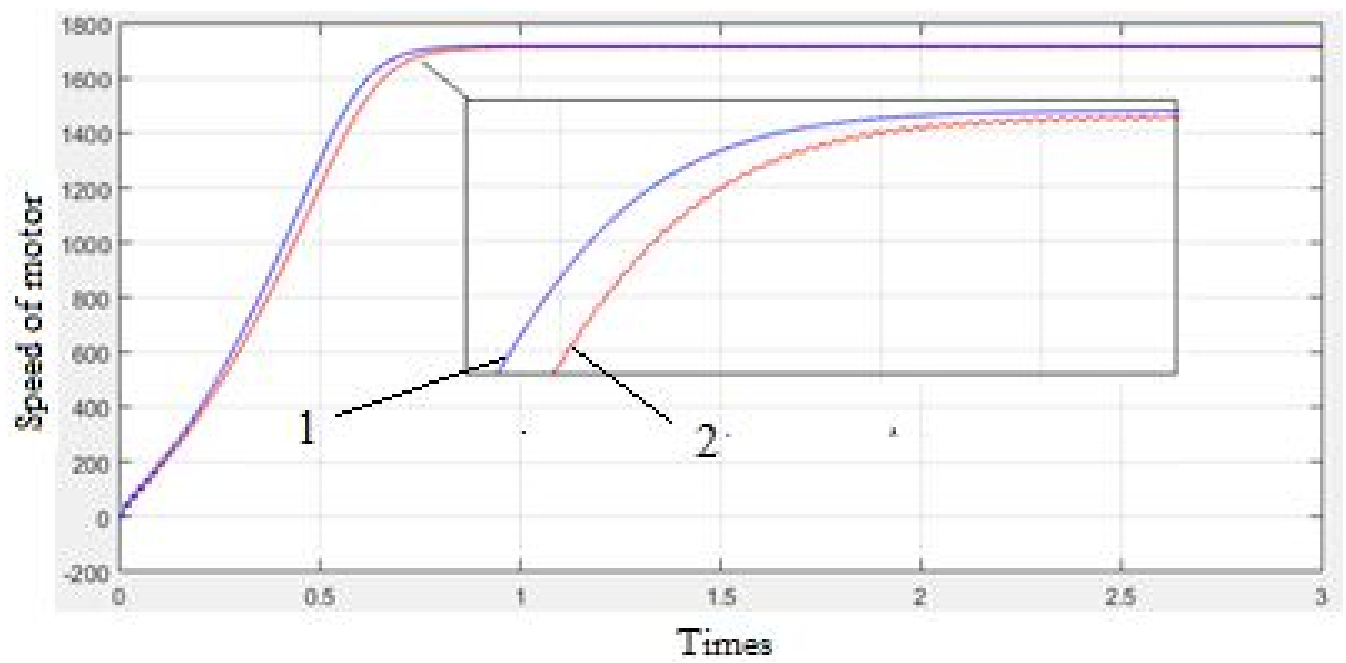

Figure 5. Motor acceleration process.

(maximum fluctuation value of stator current is $13 \mathrm{~A}$, rotor current is $20 \mathrm{~A})$. These values are significantly bigger than normal currents when the applied voltages are symmetry (stator current is only $11 \mathrm{~A}$, and the rotor current is $14 \mathrm{~A}$ ). This increase will cause undesirable heating on the motor. The simulations are unique with the theory mentioned above.

\section{Conclusion}

Through the above analysis, it was found that: the general theory of electric machines is often built on the ideal situation when the voltage source is symmetrical. However, in actual operations, the three-phase voltage on the motor 


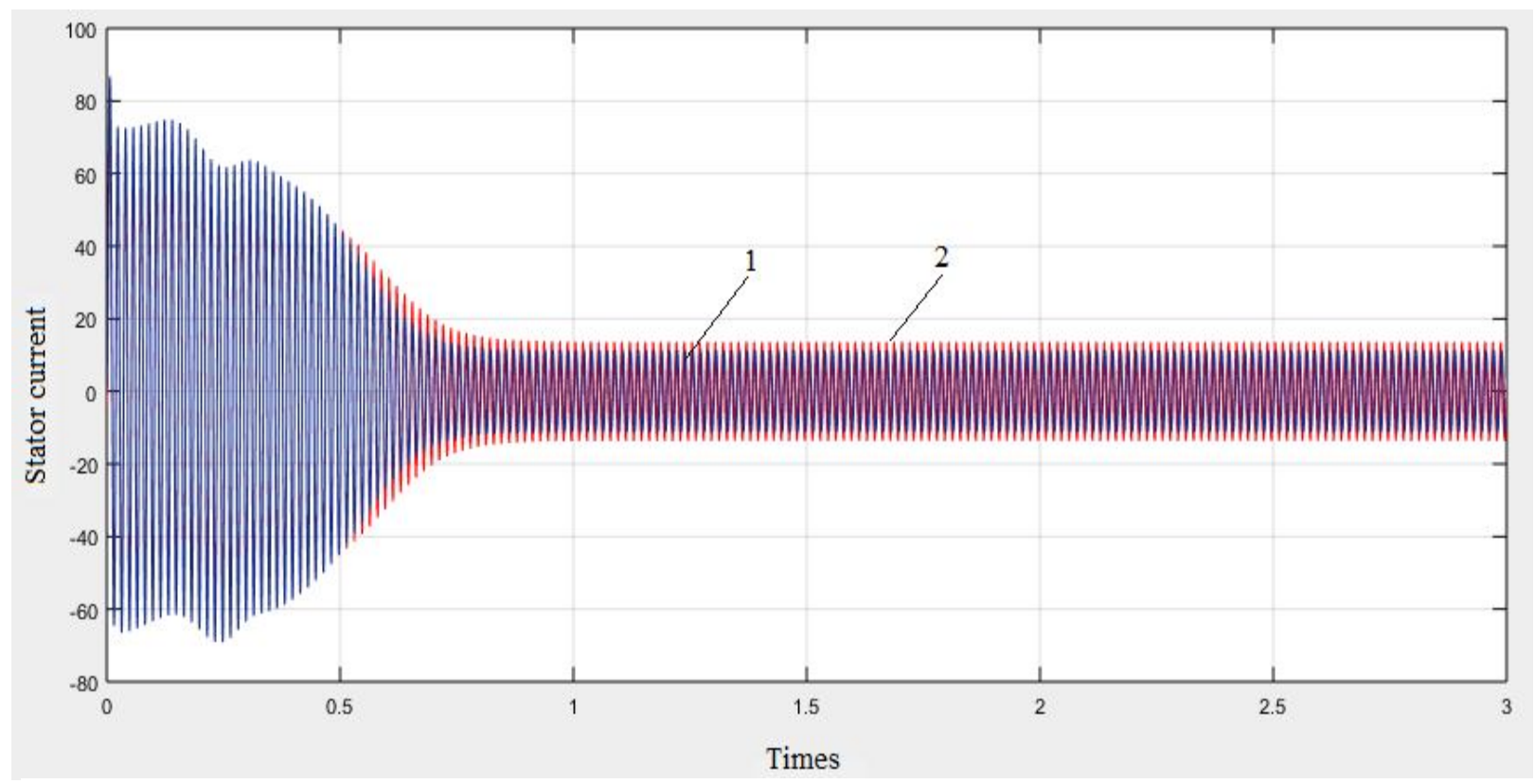

Figure 6. The stator current of the motor.

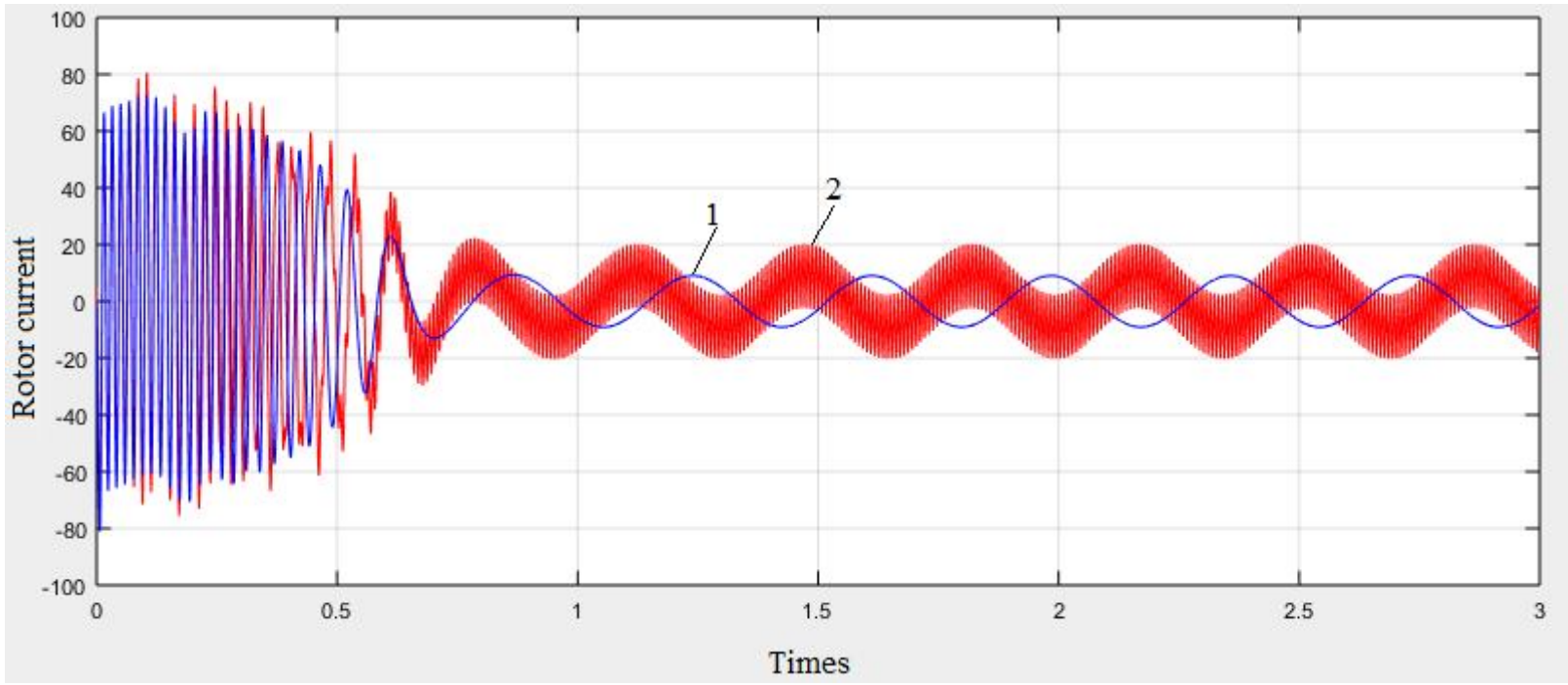

Figure 7. Motor rotor current.

is often asymmetric, which causes basic consequences:

- The motor's torque is reduced an amount equal to the negative-sequence torque, causing vibration on the motor shaft;

- The stator and rotor current are also increased to rise up the negative-sequence torque (NST) in order to compensate for the NST for maintaining the load torque. Increased current means that the loss on the motor will also increase.

Therefore, in order to improve the working efficiency of three-phase asynchronous motors, it is necessary to limit the phenomenon of voltage asymmetry on the motor. For important electric motors, there should be measures to protect the motor against voltage asymmetry to avoid the burning of the electric motor.

\section{References}

Davar Mirabbasi, Ghodratollah Seifossadat, Mehrdad Heidari. Effect of Unbalanced Voltage on Operation of Induction Motors and Its Detection. International Conference on 
Electrical and Electronics Engineering ELECO, pp 189-192, 2009.

Victoria Romanova, Sergey Khromov. Effect of asymmetry of supply voltages on asynchronous motor operation modes. E3S Web of Conferences 58, 03013 (2018). https:/ / doi.org/ 10.1051/ e3sconf/ 20185803 013.

Do Nhu Y.The impact of unsinousoidal currents to the operating efficiency of 3 phase induction motors. Earth sciences and natural resources for sustainable development- ERSD, pp109114, 2018.

V.Gia Hanh, T.Khanh Ha, P.Tu Thu, N.Van Sau. Electric machine 1. Science and Technology Publishing House. 327tr, 2001.
Prashanna Dev Bhatarai Louisiana. Study on effects of supply voltage asymmetry and distortion on induction machine. Louisiana State University, 2013.

P Giridhar Kini, R C Bansal, R S Aithal. Impact of voltage unbalance on the performance of three-phase induction motor. The South Pacific Journal of Natural Science 24(1), pp 45 $-50,2006$.

Donald W. Novotny, Syed A. Nasar. High Frequency Losses in Induction Motors. University of Wisconsin, 129tr, 1991. 
